\title{
"Dentistry for the Pregnant Patient"
}

\author{
Dr. Verdine Virginia Antony, Dr. Rahamathulla Khan \\ ${ }^{1}$ ( Department of Periodontics\& Implantology, Sirte University, Libya.) \\ 2 ( Department of Orthodontics, Sirte University, Libya.)
}

\begin{abstract}
Although not a diseased state, pregnancy has still been considered as an impediment to dental treatment. When dealing with a pregnant patient, the dental practitioner should keep in mind the various physiological changes that occur in the pregnant female and the potential effects on the fetus. The primary concern when providing dental care is to prevent genetic damage to the fetus. Two areas of dentistry have the potential risk for fetal damage, one being dental radiography and other drug administration. Other concerns are whether usage of LA with epinephrine is safe and which period is best for providing dental care. This article reviews the current considerations in the use of local anesthesia in the pregnant dental patient, their dosage, and any adverse effect on mother and fetus. It also discusses various dental procedures and the trimester during which they can be performed and the complications that could be encountered during dental treatment and their management.
\end{abstract}

Key words: Dental care, Fetus, Pregnancy.

\section{Introduction:}

Pregnancy is an important milestone in the life of a female characterized by complex physical andphysiological changes that have significant impact onalmost every organ system of the body, including the oral cavity, Hormonal, immunologic, dietary, and behavioural changes associated with pregnancy are believedto be the contributing factors. Increased levels of sex hormones, oestrogen and progesterone, are related toincreased permeability of oral vasculatures and decreased host immunocompetency. This increases the tendency and severity of oral inflammation to bacteria, physical and chemical irritations [1,2].

Pregnant women are vulnerable to common oral diseases such as periodontal disease and dental caries; if oral health is not well maintained during this period there are implications for oral health in the woman's subsequent life [3]. Changes in dietary habits and oral hygiene practices can increase the risk of tooth decay during pregnancy. The increased production of oestrogen and progesterone during pregnancy may give rise to the development of gingivitis and periodontitis attributed to increased vascular permeability and possible tissue oedema [4]. A plausible mechanism is chronic periodontal infection serve as reservoirs for Gram-negative anaerobic bacteria, their toxins as well as inflammatory mediators such as PGE2 and TNF $\alpha$, C-reactive proteins (CRP) posing potential threats to the foetal-placental unit. Sustained elevated levels of CRP and interleukins can act as insulin antagonists, interfere with insulin signaling and causing glucose intolerance and Gestational Diabetes Mellitus [5]. Evidence shows that periodontal disease is associated with gestational diabetes mellitus (GDM), which contributes to maternal and infant morbidity as well as the risk of the mother developing type 2 diabetes mellitus subsequently. Maternal periodontal disease may also increase the risk of adverse pregnancy outcomes such as pre-eclampsia, pre-term births, retarded fetal growth and low birth weight [6,7,8].Many intervention studies have documented that mechanical periodontal therapies such as scaling and root planing during the second trimester of pregnancy may reduce the risk of these adverse outcomes [9].

All pregnant women who visit antenatal clinics should be referred to the nearest public dental clinic for oral health screening and necessary care. Oral health education sessions should be delivered to the pregnant women. Oral health education sessions provide a unique opportunity to make the women aware of the importance of good oral health during pregnancy and to motivate them to attend an oral screening and have their oral health problems addressed. Traditionally, dentists offered conservative treatment options to pregnant women. Today, dental visits during pregnancy are not taboo. The pregnant patient in a dental office has unique needs; in that dental therapy has to be provided to them without undue side effects on the mother or the fetus. Dental care can be safely instituted to them provided the dentist takes the required precautions keeping in mind the changes associated with pregnancy. 


\section{Stages Of Gestation:}

The various anatomic changes in the different stages of gestation and the care required in each stage are as follows [10]:

First Trimester (1-12 weeks)

$>$ Pre-implantation stage - from conceptionto implantation is a 16 days period.

$>$ Fetal organ formation and differentiation takes place.

$>$ Organogenesis period ranges from the $17^{\text {th }}$ to the $56^{\text {th }}$ day. The exposure of the embryo to certain drugs or environmental factors can result in congenital malformations (teratogenicity) / abortion.

$>$ Exposure to environmental factors or anticancer drugs can result in spontaneous loss of the embryo.

$>$ Many dentists agree that dental treatment may not necessarily harm organogenesis, but it is best to minimize any potential risk.

$>$ Avoid all elective care but provide care as needed.

Second Trimester (13-24 weeks)

> This trimester is characterized by growthand development of fetal organ systems.So organ malformations except dentalare less likely. Risk of spontaneous abortion is lesser.

$>$ As fetal liver and kidney develop rapidly it has limited ability to metabolize drugs crossing placenta. Use of any medication should be with obstetricians consent.

> Routine dental treatment is indicated especially caries and periodontal disease control. Change in oral flora i.e. presence of Prevotellaintermedia, which compounded with poor oral hygiene and alteration of immunoresponse can cause pregnancy gingivitis.

Third trimester (25-40 weeks)

$>$ Fetal growth continues. Focus of concern is risk to the upcoming birth process and, safety and comfort of the pregnant woman. Retardation of physical or mental growth or premature labor may occur.

> Patient may be hypotensive due to pressure exerted by uterus on the Inferior Vena Cava especially in the supine position so reduced venous return and hence reduced Cardiac output (Supine Hypotensive syndrome). Rolling to left side relieves the pressure and patient consciousness is restored.

$>$ If treatment is to be rendered at this time, keep short appointments or allow shifting in the mother's position every 3-7 minutes. In addition, if the situation is stressful, premature labor can be induced.

\section{Systemic Changes In Pregnancy:}

Complex hormonal interactions cause profound physiologic changes in pregnant women. There is increase estrogen by 10 folds and progesterone by 30 folds. Increased hormonal secretion and fetal growth causes several systemic as well as physical changes in pregnant women. The changes occurring during pregnancy are:

Hormonal Changes :Increased progesterone levels cause change in oral flora and induction of liver microsomal enzymes causing faster metabolism of certain drugs.

Physiologic changes -Blood volume is increased by 50\%. This causes changes in drug metabolism and elimination due to increased blood flow and also predisposes patient to anemia and neutrophilia. Iron supplements are hence often required.

\section{III.1.Cardiovascular system [11,12]}

$>$ Increase in blood volume by an average of $50 \%$

$>$ Anemia due to increased blood volume (20\% of women)

$>$ Decrease in pulse by $10-15$ beats per minute

$>$ Systemic murmur occurs in $90 \%$ pregnancies which disappears shortly after delivery

$>$ Increased cardiac output

> Supine hypotension syndrome may occur. It occurs when inferior vena cava gets compressed while patient is lying in flat supine position, the uterus compresses the inferior vena cava which decreases rectus volume to the heart resulting in reduced perfusion of uterus leading to fetal hypoxia.

$>$ Symptoms of supine hypotension are sweating, nausea and weakness. Other symptoms can be drop in blood pressure bradycardia and possible loss of consciousness. Supine Hypotensive Syndrome may be prevented by elevating the right hip by $10-12 \mathrm{cms}$ so that the weight is taken off the major vessels and by rolling patient onto the left lateral position.

\section{III.2.Respiratory system}

$>$ Diaphragm rises about $4 \mathrm{~cm}$.

$>$ Decreased residual volume 
Increased awareness of a desire to breathe is common- may be interpreted as dyspnea.

$>$ Increased estrogen in blood causes engorgement of the nasal capillaries and rhinitis in pregnant women

Frequent nosebleeds \& predisposition to upper respiratory infection.

III.3.Gastrointestinal system $[13,14]$

Dastric emptying \& intestinal transit times are delayed.

$>$ Heart burn / reflux is common

$>$ Nausea and vomiting

> For pregnant patient with Hyper-emesis gravidarium (excessive and uncontrolled vomiting) morning appointments should be avoided.

$>$ They should be seated in a semi-supine or comfortable position

$>$ In case of vomiting, the procedure should be stopped immediately \& the patient should be repositioned upright

III.4.Renal System [15]

$>$ Increased Glomerular Filtration Rate and renal plasma flow by about $50 \%$

$>$ Nocturia

$>$ Increased frequency in renal flow and reduced bladder capacity from uterine growth

$>$ It is advisable to ask the patient to void the bladder just prior to starting the dental procedure.

III.5.Endocrine Changes [16]

$>$ Estrogen, progesterone, human gonadotropin are increased.

$>$ Thyroxin, steroid and insulin level are also increased.

$>$ Estrogen \& progesterone are insulin antagonists, so increased levels of these hormones lead to insulin resistance. Thus insulin levels are elevated in pregnant patients.

$>$ About $45 \%$ of women fail to produce sufficient amount of insulin to overcome this antagonist action \& thus develop gestational diabetes.

III.6.Hematological change $[17,18]$

$>$ Increased Red Blood Cell count, increased Erythrocyte Sedimentation Rate, decrease in Hemoglobin

$>$ Increased White Blood Cell count

$>$ Increased circulatory catecholamine and cortisol lead to leukocytosis

$>$ Increase in Coagulation factors except factor XI \& XIII (anticlotting factor)

$>$ Pregnancy is a hypercoagulable state $\&$ increased risk for thromboembolism

$>$ The proximity of fetal and maternal circulations increases the risk of isoimmunization in a Rhonegative woman with a Rho-positive fetus

\section{Oral Health Problems Related To Pregnancy [19,20]}

Most common oral manifestation (50-100\% of women) are generally caused by hormonal and vascular changes of pregnancy.

* Pregnancy gingivitis: Occurs commonly during the $2^{\text {nd }}$ to $8^{\text {th }}$ months of pregnancy. The cause of pregnancy gingivitis is multifaceted namely increased plasma female sex hormones, alteration in dental plaque and colonisation of Prevotella intermedia in the subgingival plaque together with an alteration of the immune response. Treatment involves oral prophylaxis and maintenance of good oral hygiene. (FIGURE-1)

- Pregnancy granuloma: Occurs in upto 5\% of women. It is most common in the buccal surface of the maxillary anterior region and usually occurs in an area of gingivitis. It presents as purplish or bluish in color, may be ulcerated and bleeds easily treatment involves oral prophylaxis and maintenance of good oral hygiene.. The excision of the lesion might be required if it persists after delivery. (FIGURE-2)

- Increased Tooth Mobility: During pregnancy hormones like estrogen and progesterone have seen to increase ligament laxity in joints and can also cause increased mobility of teeth. Severe mobility indicates severe periodontal disease and should be evaluated by a dentist as soon as possible.

* Dental Caries: Many women experience nausea or hypoglycemia during pregnancy, which necessitates the consumption of between-meal snacks. Commonly promoted foods such as crackers may be high in starches (fermentable carbohydrates) that promote tooth decay. This increased frequency of food consumption and increase in carbohydrate intake can promote tooth decay by increasing the acid production of decay-causing bacteria. 
* Perimylolysis: or acid erosion of teeth may occur if "morning sickness" or esophageal reflux is severe and involves repeated vomiting of the gastric contents. Severe reflux may cause scarring of the esophageal sphincter and the patient may become a more likely candidate for GERD later in life.

* Xerostomia: is a frequent complaint among pregnant women

* A rare finding in pregnancy is ptyalism or sialorrhea. This excessive secretion of saliva usually begins at 2 to 3 weeks of gestation and may abate at the end of the first trimester. The etiology of ptyalism has not been identified, but it may occur because of the inability of nauseated gravid women to swallow normal amounts of saliva rather than from a true increase in the production of saliva.

* Because pregnancy places the woman in an immunocompromised state, the clinician must be aware of the total health of the patient. Gestational diabetes, leukemia, and other medical conditions may appear during pregnancy.

* Periodontal Disease and Preterm Labor [7,8]: Numerous studies till date indicates that periodontal disease is associated with an increased risk of preterm labor. The onset of periodontal disease or activated chronic disease is caused by gram-negative bacteria, which may cause recurrent bacteremias and release of lipopolysaccharide endotoxin, which leads to hepatic acute inflammatory response. This in turn leads to production of cytokines and biological mediators such as prostaglandins (PGE2) and interleukins (IL-1, IL6 ) as well as the systemic production of serum antibodies. These mediators can initiate labor.

\section{Guidelines for Dental Treatment During Pregnancy [21,22]}

* Preventive, restorative, and rehabilitative programs should continue throughout pregnancy.

* Oral prophylaxis, and topical fluoride treatment should be performed regularly.

* Elective dental treatment is best avoided in the first trimester, and ideally, any elective procedures should be postponed until after delivery.

* Dental radiographs should be avoided wherever possible.

* Sedation inducement involving nitrous oxide and oxygen, or intravenous diazepam, should be avoided wherever possible.

* In advanced pregnancy, the mother's posture should be comfortable so that fetal mass does not press on the inferior vena cava.

* Prolonged body temperature elevation should be avoided, as it may affect the developing cells in the fetus.

TABLE 1:Scheduling of Dental treatment during pregnancy (Little and Falace)

\begin{tabular}{|c|c|c|}
\hline First Trimester & Second Trimester & Third Trimester \\
\hline 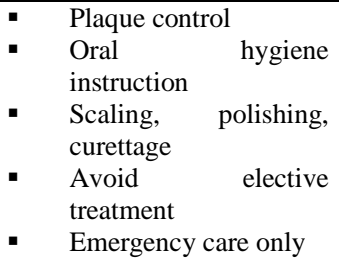 & $\begin{array}{ll}\text { - } & \text { Plaque control } \\
\text { - } & \text { Oral hygiene instruction } \\
\text { - } & \text { Scaling, polishing,curettage } \\
\text { - } & \text { Routine dental care }\end{array}$ & $\begin{array}{ll}\text { - } & \text { Plaque control } \\
\text { - } & \text { Oral hygiene instruction } \\
\text { - } & \text { Scaling,polishing,curettage } \\
\text { - } & \text { Routine dental care } \\
\text { - } & \text { After middle of third trimester elective } \\
& \text { care should be avoided }\end{array}$ \\
\hline
\end{tabular}

\section{Radiation in Pregnancy}

Most dentists do not recommend routine radiographs during pregnancy. However, minimal radiographs may be necessary during pregnancy to treat dental emergencies; in such cases adequate radiation protection measures such as lead aprons and thyroid collars should be provided for the patient. The dose given and time of gestation are important aspects to be considered. Doses <5-10 rads (cGy) are not teratogenic. The fetus is most susceptible to radiation between the 2 nd and 6 th week of gestation. A single dental radiograph exposes the patient to 0.01 millirads of radiation; relatively this amount is 40 times less than the daily dose acquired from cosmic radiation. Therefore, diagnostic radiation should not be withheld during pregnancy.

\section{Local anesthesia}

Injected local anesthetics can cross the placenta. However, small amounts of lidocaine used in dentistry probably will not adversely affect a developing fetus. 
VI. Risk Factor Classification And Drug Usage [23,24,25,26]

The FDA has established five categories for drug-related risks to pregnant women.

TABLE 2: FDA Pregnancy Risk Factor classification and usage of drugs.

\begin{tabular}{|l|l|}
\hline Definition & \multicolumn{1}{c|}{ Description } \\
\hline Category A & $\begin{array}{l}\text { Controlled Studies in women fail to demonstrate a risk to the fetus in the first trimester and the possibility } \\
\text { of fetal harm appears remote }\end{array}$ \\
\hline Category B & $\begin{array}{l}\text { Either animal-reproduction studies have not demonstrated fetal risk but there are no controlled studies in } \\
\text { pregnant women, or animal-reproduction studies have shown an adverse effect (other than a decrease in } \\
\text { fertility) that was not confirmed in controlled studies in women in the first trimester (and there is no } \\
\text { evidence of a risk in later trimesters). }\end{array}$ \\
\hline Category C & $\begin{array}{l}\text { Either studies in animals have revealed adverse effects on the fetus (teratogenic or embryoicidal, or other) } \\
\text { and there are no controlled studies in women, or studies in women and animals are not available. Drugs } \\
\text { should be given only if the potential benefit justifies the potential risk to the fetus. }\end{array}$ \\
\hline Category D & $\begin{array}{l}\text { There is positive evidence of human fetal risk, but the benefits from use in pregnant women may be } \\
\text { acceptable despite the risk (e.g., if the drug is needed in a life-threatening situation or for a serious disease } \\
\text { for which safer drugs cannot be used or are ineffective). }\end{array}$ \\
\hline Category X & $\begin{array}{l}\text { Studies in animals or humans have demonstrated fetal abnormalities, or there is evidence of fetal risk } \\
\text { based on human experience, or both, and the risk of the use of the drug in pregnant women clearly } \\
\text { outweighs any possible benefit. The drug is contraindicated in women who are or may become pregnant. }\end{array}$ \\
\hline
\end{tabular}

TABLE 3: FDA drug classification for pregnancy

\begin{tabular}{|c|c|c|}
\hline DRUGS & FDA CATEGORY & USE DURING PREGNANCY \\
\hline \multicolumn{3}{|l|}{ LOCAL ANESTHESIA } \\
\hline Lidocaine & B & YES \\
\hline Mepivacaine & $\mathrm{C}$ & YES (with caution) \\
\hline Prilocaine & B & YES \\
\hline Bupivacaine & $\mathrm{C}$ & YES (with caution) \\
\hline Ethiodocaine & $\mathrm{B}$ & YES \\
\hline \multicolumn{3}{|l|}{ ANALGESICS } \\
\hline Aspirin & $\mathrm{C} / \mathrm{D}$ & $\mathrm{NO}$ \\
\hline Acetaminophen & $\mathrm{B}$ & YES \\
\hline Ibuprofen & $\mathrm{B} / \mathrm{C}$ & Avoid in $3^{\text {rd }}$ trimester \\
\hline Cox-2 inhibitors & $\mathrm{C}$ & Avoid in $3^{\text {rd }}$ trimester \\
\hline Codeine & $\mathrm{C}$ & $1^{\text {st }}$ and $2^{\text {nd }}$ trimester \\
\hline Oxycodone & $\mathrm{B} / \mathrm{C}$ & YES \\
\hline Morphine & $\mathrm{B}$ & YES \\
\hline Fentanyl & $\mathrm{B}$ & YES \\
\hline Naproxen & $\mathrm{B} / \mathrm{D}$ & Not used in $2^{\text {nd }}$ half of $3^{\text {rd }}$ trimester \\
\hline \multicolumn{3}{|l|}{ ANTIBIOTICS } \\
\hline Amoxicillin & $\mathrm{B}$ & YES \\
\hline Metronidazole & B & YES \\
\hline Erythromycin & $\mathrm{B}$ & YES \\
\hline Pencillin V & $\mathrm{B}$ & YES \\
\hline Cephalosporin & B & YES \\
\hline Gentamycin & $\mathrm{C}$ & YES \\
\hline Clindamycin & B & YES \\
\hline Tetracyclins & $\mathrm{D}$ & $\mathrm{NO}$ \\
\hline Chlorhexidine & $\mathrm{B}$ & YES \\
\hline \multicolumn{3}{|l|}{ CORTOCOSTEROIDS } \\
\hline Prednisolone & $\mathrm{B}$ & YES \\
\hline \multicolumn{3}{|l|}{ ANTIFUNGALS } \\
\hline Nystatin & $\mathrm{B}$ & YES \\
\hline Clotrimaxozole & $\mathrm{B}$ & YES \\
\hline Fluconazole & $\mathrm{C}$ & WITH CAUTION \\
\hline Ketconazole & $\mathrm{C}$ & WITH CAUTION \\
\hline \multicolumn{3}{|l|}{ SEDATIVES } \\
\hline Benzodiazapenes & $\mathrm{D}$ & $\mathrm{NO}$ \\
\hline Barbiturates & $\mathrm{D}$ & $\mathrm{NO}$ \\
\hline $\mathrm{N}_{2} \mathrm{O}$ & Not designated & CONTROVERSIAL \\
\hline
\end{tabular}

* Category A includes drugs that have been studied in humans and have evidence supporting their safe use. Category B drugs show no evidence of risks in humans. Category $\mathrm{C}$ drugs cannot be ruled out for teratogenicrisks. Category D drugs have demonstrated risks to humans. Category $\mathrm{X}$ drugs have agents that are shown to be harmful to the mother and fetus. 
*Drugs in Categories A and B can be prescribed during pregnancy, Category $\mathrm{C}$ drugs should be used with caution, and Category D and Category X drugs should be avoided as contraindicated. Less than 20 percent of all drugs classified by the FDA fall into Category A or B.

- Conventional dose of ampicillin and cephalosporins are safest as long as no allergy is present to them. The dosage needs to be doubled during pregnancy if used for systemic infections except UTI; as increased progesterone levels induce hepatic microsomal enzymes, resulting in rapid metabolism and increased renal plasma flow causing rapid elimination of drugs like ampicillin, gentamicin, cephalexin.

- Aspirin, Benzodiazepines, metronidazole doses need not be altered.

- Aspirin for long-term use in pregnancy is best avoided as it can produce post partum hemorrhage and early closure of ductus arteriosus. Aspirin is however useful in preventing eclampsia prior to delivery.

- Pregnant patients should not be treated with Tetracycline as this could lead to discolouration of the baby's teeth.

- Paracetamol is the safest analgesic to be given.

\section{VII.1. SYNCOPE}

\section{Obstetrical Emergencies In The Dental Office [22,25,27]}

The most common symptoms of syncope are hypotension, hypoglycemia, anemia, and dehydration. Neurogenic disorders may cause syncope. The treatment for a pregnant patient who syncopes includes administering oxygen while maintaining vital signs. Sugar containing fluids can relieve mild dehydration and hypoglycemia.

\section{V11.2. MORNING SICKNESS (HYPEREMISIS GRAVIDARUM)}

The pregnant dental patient may experience bouts of nausea and vomiting. The dental surgeon should therefore be prepared by having oropharyngeal suction readily available. Should any object become lodged in the airway after vomiting, the dentist can use only chest compression during advanced stages of pregnancy to remove the foreign body blocking the airway (American Heart Association guidelines).

\section{VII.3. SEIZURE}

Seizure in pregnant patients is considered eclampsia (toxemia of pregnancy), which is a medical emergency. Signs of eclampsia are generalized edema, elevated blood pressure (systolic above 140 and diastolic above 90), severe headaches, blurred vision, or abdominal pain. Seizure in association with aspiration of gastric contents is the leading cause of maternal death. Hypoxia is the leading cause of fetal death. Should a seizure develop during dental treatment, the patient should be administered oxygen by placing her on her left lateral position, applying suction to the airway, and providing emergency transport to a hospital.

\section{4. BLEEDING AND CRAMPING}

Regardless of fetal age, vaginal bleeding is indicative of problems for the mother and can be a sign of impending miscarriage. Patients with ruptured amnion and chorion membranes, active vaginal bleeding, or painful contractions should be placed on their side, administered oxygen, and transported to the nearest hospital

\section{VII.5.OTHER COMPLICATIONS}

Pregnant women with anti-phospholipid syndrome are at an increased risk for thrombo-embolisim, so they should be placed on subcutaneous low molecular weight heparin (LMWH). These patients must be hospitalized for dental care.

\section{Intrauterine Dentistry [28]}

Intrauterine Dentistry is a highly relevant subject of our time because its preventive measures can avoid several diseases such as dental caries. In the WHO Bulletin "Health for all in the year 2000", pregnant women were advised to avoid the intake of sugar from the 4th month of pregnancy on, due to the fact that the baby's taste sensory organs start developing. If at this stage the mother consumes too much sugar, her child will certainly have great preference for sweetened foods.

\section{Conclusion}

Due to the myriad health conditions and complications that can surround a pregnancy and to ensure the health of the mother and fetus, dental surgeons should adopt precautions when treating a pregnant patient in the dental chair

Traditionally, general dentists have been reluctant to treat pregnant patients due to uncertainty of the risks that might be imposed on both the mother and the fetus. However, preventive, emergency, and routine 
dental procedures are all suitable during various phases of a pregnancy, with some treatment modifications and initial planning.

To Summarise,

1. Stress on oral hygiene maintenance. Annual dental exams, patient education and routine teeth cleanings are encouraged so as to reduce the risk of a dental emergency arising during pregnancy. Visits to the dentist should be an integral part of prenatal checkups.

2. Provide only necessary treatment. Dental care should be minimized mostly for the comfort of the expectant mother. Elective treatment like cosmetic dentistry can be postponed until after delivery.

3. Consult an obstetrician if needed. An ideal model of treatment for pregnant women must include integrated and multi-professional treatment, in which general dentists, pediatric dentists, gynecologist-obstetricians, pediatric physicians and nutritionists work together with the patient.

4. Keep appointments short especially in later months to prevent supine hypotensive syndrome or induce premature labor.

\section{References}

[1] Fiese R, Herzog S. Issues in dental and surgical management of the pregnant patient. Oral Surg Oral Med Oral Pathol 1988;65:2927.

[2] Martin C. Varner MW. Physiologic changes in pregnancy: surgical implications. ClinObatetGynecol 1994;37:241-55.

[3] Pregnancy and menopause in dentistry: J ClinExp Dent. 201 1;3(2):e135-144.

[4] Theunissen TM, Parer JT. Fluid and electrolytes in pregnancy. ClinObstetGynecol 1994;37:3-15.

[5] Xiong X, Elkind-Hirsch KE, Vastardis S, Delarosa RL, Pridjian G, Buekens P. Periodontal disease is associated with gestational diabetes mellitus: a case control study. Journal of Periodontology 2009; 80(11): 1742-1749.

[6] Buduneli N, Baylas H, Buduneli E, Turkoglu O, Kose T, Dahlen G. Periodontal infections and pre-term low birth weight: a casecontrol study. J ClinPeriodontol 2005;32(2):174-81.

[7] Lupez NJ, Smith PC, Gutierrez J. Periodontal therapy may reduce the risk of preterm low birth weight in women with periodontal disease: a randomized controlled trial. J Periodontol 2002;73:91 1-24.

[8] Jeffcoat MK, Hauth JC, Geurs NC, et al. Periodontal disease and preterm birth: results of a pilot intervention study. J Periodontol 2003;74(8):1214-8.

[9] Madianos PN, Lieff S, Murtha AP, et al. Maternal periodontitis and prematurity, II: maternal infection and fetal exposure. Ann Periodontol 2001;6(1):175-82.

[10] Barton WM, Lindheimer MD. Medical disorders during pregnancy. 2nd ed. St Louis: Mosby; 1995. p. 129. 5. Thornburg KL, Jacobson SL, Giraud GD, Morton MJ. Hemodynamic changes in pregnancy. SeminPerinatol 2000;24:114.

[11] ClappJF 3rd, Capeless E. Cardiovascular function before, during, and after the first and subsequent pregnancies. Am J Cardiol 1997;80:1469-73

[12] Duvekot JJ. Peeters LL. Maternal cardiovascular Surv 1994;49(Suppl): S1-14. hemodynamic adaptation to pregnancy. ObstetGynecol

[13] Miller MC. The pregnant dental patient. J Calif Dent Assoc. 1995;23(8):63-70

[14] Tarsitano BF, Rollings RE. The pregnant dental patient: evaluation and management. Gen Dent. 1993;41(3):226-234

[15] Duvekot JJ' Peeters LLH. Renal hemodynamics and volume homeostasis in pregnancy. ObsterGynecolSurv 1994;49:830-9.

[16] Weiss G. Endocrinology of parturition. J ClinEndocrinol Metab2000;85:4421-5.

[17] Theunissen TM, Parer JT. Fluid and electrolytes in pregnancy. ClinObstetGynecol 1994;37:3-15.

[18] Clark SL, Coiron DB, Lee W, Bishop C, Hill T, Southwidc J, ct al. Central hemodynamic assessment of normal term pregnancy. Am J ObstetGynecol 1989;161:1439-42.

[19] Wasylko L, Matsui D, Dykxhoorn SM, Reider MJ, Weinberg S. A review of common dental treatments during pregnancy: implications for patients and dental personnel. J Can Dent Assoc. 1998;64(6):434-439.

[20] Lawrenz DR, Whitley BD, Helfrick JF. Considerations in the management of maxillofacial infections in the pregnant patient. J Oral Maxillofac Surg. 1996;54(4):474-485.

[21] Lyon LZ, Wishan MS. Management of pregnant dental patients. Dent Clin North Am. 1965 Nov;623-634.

[22] Little JW, Falace DA. Dental management of medically compromised patient. 4th ed. St. Louis (MO): Mosby; 1993. P. $383-389$.

[23] National Health and Medical Research Council. Guidelines for dental treatment: dentistry and pregnancy. Statement. Australian Dent J. 1984;29(4):265-266.

[24] Wynn RL, Meiler TF, Crossley HL. Drug information handbook for dentistry, 1999-2000. 5th ed. Hudson (OH): Lexi-Comp; 1999.

[25] Epstein JB, Chong S, Le ND. A survey of antibiotic use in dentistry. J Am Dent Assoc. 2000 Nov;131(11):1600-9.

[26] Agwuh KN, MacGowan A. Pharmacokinetics and pharmacodynamics of the tetracyclines including glycylcyclines. J AntimicrobChemother. 2006 Aug;58(2):256-65.

[27] Tarsitano BF, Rollings RE. The pregnant dental patient: evaluation and management. Gen Dent. 1993;41(3):226-234

[28] Gonzaga HF, Buso L, Jorge MA. Intrauterine Dentistry: An Integrated Model of Prevention BrazDentJ (2001) 12(2): 139-142 ISSN 0103-6440. 
LEGENDS FOR PICTURES:

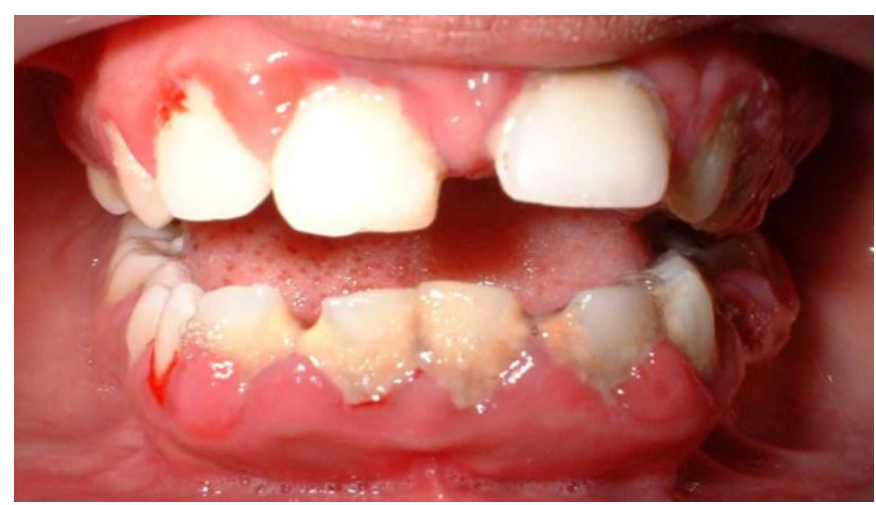

FIGURE-1: PREGNANCY GINGIVITIS

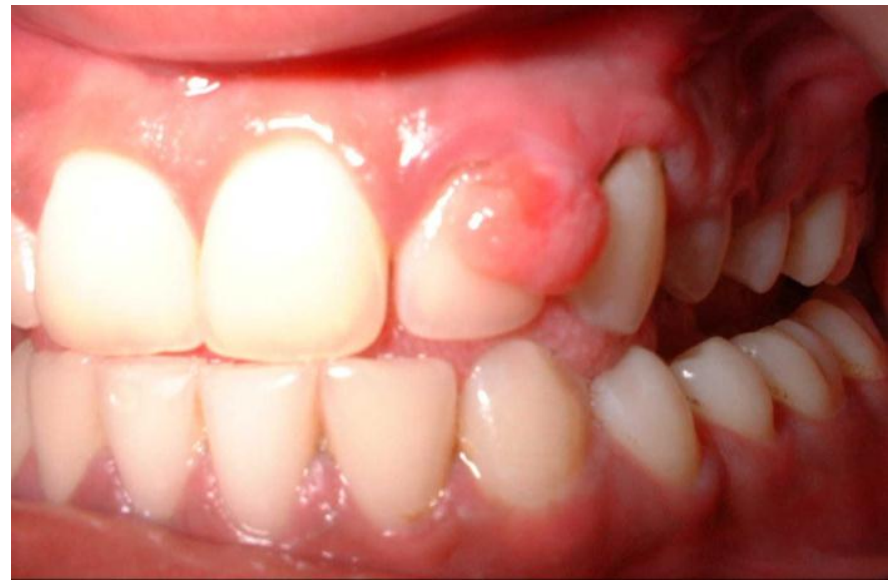

FIGURE-2: PREGNANCY GRANULOMA 